\title{
An ultrastructural study of in-vitro interaction of guinea-pig and mouse blastocysts with extracellular matrices
}

\author{
R. J. Wordinger*, A.-M. Brun-Zinkernagel and T. Jackson \\ Department of Anatomy and Cell Biology, University of North Texas, Texas College of Osteopathic \\ Medicine, Fort Worth, TX 76107-2690, USA
}

\begin{abstract}
Summary. Guinea-pig (intrusive) and mouse (displacement) blastocysts display different cellular mechanisms of implantation. Blastocysts were placed in CMRL-1066 supplemented with either 10 or $20 \%$ fetal calf serum, $0 \cdot 1 \mathrm{M} \mathrm{L}$-glutamine and antibiotics and then transferred to dishes previously coated with either Matrigel $\mathrm{M} M$ or type I collagen. After culture for 48 or $72 \mathrm{~h}$, the dishes were processed for transmission electron microscopy. Blastocysts had attached to both extracellular matrices by $48 \mathrm{~h}$. Matrigel $1 M$ elicited minimal trophoblast cell activity. Trophoblast cell projections were oriented parallel to the Matrigel(im) and displayed little invasive activity, but trophoblast cells displayed active interaction with type I collagen. By $72 \mathrm{~h}$, trophoblast cells exhibited slender, anastomosing projections which extended into the collagen matrix. Bundles of microfilaments running parallel with the long axis of the projections were observed. The morphology of type I collagen was altered in the immediate vicinity of the trophoblast projections. The projections interdigitated and desmosomes developed between processes. Projections appeared to meet, fuse and entrap matrix. These results suggest that trophoblast cells do not significantly interact with MatrigeliM, but penetrate into type I collagen.
\end{abstract}

Keywords: trophoblast; extracellular matrices; ultrastructure; in vitro; guinea-pig; mouse

\section{Introduction}

The exact cellular events associated with blastocyst implantation differ among animals. Several distinct methods of trophoblast cell interaction with the endometrium have been described by Schlafke \& Enders (1975). Displacement implantation is found in mice and rats. It is characterized by evidence of cell death in the epithelial layer and the subsequent detachment of individual or groups of cells (Finn \& Hinchliffe, 1964). Trophoblast projections end at the basal lamina and send out projections that undermine adjacent cells. Subsequently, the basal lamina is penetrated by processes from the decidualized stromal cells (Schlafke et al., 1985). Thus, the initial penetration of the endometrium by trophoblast cells is a passive event. Intrusive implantation is found in guinea-pigs and ferrets and possibly also in higher primates, including man, and is characterized by trophoblast cell processes which penetrate between epithelial cells, pause at the basal lamina and then invade through the basal lamina into the underlying connective tissue stroma (Enders \& Schlafke, 1972). Thus, the initial penetration of the endometrium by trophoblast cells is a more invasive event.

Implantation of the blastocyst involves many complex cellular mechanisms including blastocyst interaction with various extracellular matrices. These include the basal lamina underlying the

*Reprint requests and correspondence. 
endometrial luminal epithelium (Schlafke et al., 1985) and the maternal blood vessels (Welsh \& Enders, 1987) as well as the interstitial connective tissue stroma. In intact animals, it is difficult to obtain specific information concerning interactions between trophoblast cells and extracellular matrices of the endometrium. In-vitro systems which mimic aspects of implantation would allow us to investigate the mechanisms involved in blastocyst implantation.

This experiment used transmission electron microscopy to compare and contrast the in-vitro interaction of mouse (displacement) and guinea-pig (intrusive) blastocysts with the following extracellular matrices: (a) Matrigel(iM), a reconstituted extract of the basal lamina and (b) type I collagen, a component of the interstitial connective tissue stroma.

\section{Materials and Methods}

Animals and housing. Virgin, adult CD-1 male and female mice (Charles River Laboratories, Inc., Wilmington, MA, USA) and Hartley male and female guinea-pigs (Hilltop Lab Animals Inc., Scottdale, PA, USA) were utilized for mating purposes. All animals were housed in a controlled environment at $22^{\circ} \mathrm{C}$ and a $14-\mathrm{h}$ light $/ 10-\mathrm{h}$ dark cycle (lights on at 06:00 h and off at 20:00 h) and food and water ad libitum.

Superovulation and recovery of mouse blastocysts. Female mice were induced to ovulate by the intraperitoneal injection of 5 iu of pregnant mares' serum gonadotrophin (PMSG) (National Pituitary Agency, Baltimore, MD, USA) followed $44 \mathrm{~h}$ later by $5 \mathrm{iu}$ of human chorionic gonadotrophin (hCG) (Sigma Chemical Co., St Louis, MO, USA). Injected female mice were housed overnight with individual males. Mating was verified the following morning by the presence of a copulatory plug. For the collection of blastocysts, female mice were killed $96 \mathrm{~h}$ after the detection of a copulatory plug. Uteri were removed, and blastocysts recovered by flushing each uterine horn with $0 \cdot 1 \mathrm{ml}$ of culture medium. After flushing from the uterus, blastocysts were examined microscopically and those which appeared normal were collected and pooled. Only blastocysts displaying the following characteristics were cultured: (i) an inner cell mass, (ii) a blastocyst cavity, (iii) an outer layer of trophoblast cells which enclosed the inner cell mass and blastocyst cavity, (iv) blastomeres of equal size and (v) a distinct, intact zona pellucida. Embryos which did not meet these criteria were not included in the experiments.

Natural mating and embryo recovery. Female guinea-pigs were housed with individual males and examined daily for the presence of a copulatory plug (Day 1) indicating mating. Female guinea-pigs were killed by decapitation on the afternoon of Day 5 of pregnancy. Ovaries were examined, with a dissecting microscope, for the number of ovulation sites. Uteri were removed and blastocysts recovered by flushing each uterine horn with $0.5 \mathrm{ml}$ of culture medium. Blastocysts were examined microscopically and normal blastocysts (see above criteria) from each animal were collected and pooled.

In-vitro embryo culture. Pooled mouse and guinea-pig blastocysts were transferred to $35 \times 10 \mathrm{~mm}$ sterile Falcon plastic culture dishes (Beckton Dickinson Labware, Oxnard, CA, USA) containing $2.0 \mathrm{ml}$ CMRL-1066 culture medium (Flow Laboratories Inc., McLean, VA, USA) supplemented with 10 or $20 \%$ heat-inactivated fetal calf serum (Hyclone Laboratories, Logan, UT), 1.0mm glutamine, 1.0mm sodium pyruvate, penicillin $(100 \mathrm{U} / \mathrm{ml})$ and streptomycin $(50 \mathrm{mg} / \mathrm{ml})$. Blastocysts were incubated at $37^{\circ} \mathrm{C}$ in a continuous flow atmosphere of $95 \%$ air and $5 \%$ carbon dioxide.

Because healthy mouse blastocysts will hatch from the zona pellucida in vitro, they were transferred directly to the surface of either Matrigel (im) or type I collagen pads. All pads were examined after $48 \mathrm{~h}$ and unattached blastocysts were removed. Pads were then either processed for electron microscopy or allowed to continue in culture for another $24 \mathrm{~h}$. The zona pellucida of individual guinea-pig blastocysts was removed by exposure to a solution of $0.5 \%$ pronase (Sigma Chemical Co., St Louis, MO, USA) dissolved in phosphate-buffered saline (PBS) for $2-5 \mathrm{~min}$ at $37^{\circ} \mathrm{C}$. Following the enzymatic removal of the zona pellucida, guinea-pig blastocysts were washed in culture medium and then transferred to the surface of either Type I collagen or Matrigel

Of 28 guinea-pig blastocysts free of their zonae pellucidae, 18 were placed on type I collagen pads; after $48 \mathrm{~h}$ in culture, 11 blastocysts $(61 \%)$ were attached. The remaining 10 blastocysts were placed on Matrigel $(0)$ pads; after $48 \mathrm{~h}$ in culture, $6(60 \%)$ were attached to the surface of the pad. All 17 attached blastocysts were examined by electron microscopy. Of 98 mouse blastocysts encased by zonae pellucidae, 58 were placed on type I collagen pads; after $48 \mathrm{~h}$ in culture, $40(70 \%)$ had hatched from the zona pellucida and attached to the surface of the pad. The remaining 40 blastocysts were placed on Matrigel pads; after $48 \mathrm{~h}$ in culture, $20(50 \%)$ had hatched from the zona pellucida and attached to the surface of the pad. All 60 attached blastocysts were examined by electron microscopy.

All guinea-pig and mouse blastocysts not attached by $48 \mathrm{~h}$ in culture were considered abnormal and were removed. Pads were then either processed for electron microscopy or allowed to continue in culture for another $24 \mathrm{~h}$ before being processed for electron microscopy. At least three regions per blastocyst were sectioned and examined. 
Preparation of type I collagen pads. Type I collagen was purchased from Collaborative Research Inc. (Bedford, MA, USA); the final concentration used was $1.5 \mathrm{mg} / \mathrm{ml}$. All components were kept at $4^{\circ} \mathrm{C}$. The following components were added in order to a sterile $15-\mathrm{ml}$ centrifuge tube: $1.0 \mathrm{ml}$ sterile water, $0.5 \mathrm{ml} 10 \times$ Dulbecco's modified Eagle's medium, $2.0 \mathrm{ml}$ type I collagen solution and $0.5 \mathrm{ml} 0.1 \mathrm{M} \mathrm{NaOH}$. The mixture was shaken vigorously for $3 \mathrm{~s}$ and then $200 \mu \mathrm{l}$ of the solution was transferred using a sterile pipette to sterile Permanox (Nunc, Inc., Naperville, IL, USA) tissue culture dishes $(35 \times 10 \mathrm{~mm})$. The dishes were then transferred to an incubator at $37^{\circ} \mathrm{C}$ for $30 \mathrm{~min}$ where the collagen solution polymerized. Following polymerization, the type I collagen pads were rinsed with culture medium and left to equilibrate overnight in the incubator. They were rinsed with fresh medium before the addition of mouse or guinea-pig blastocysts.

Preparation of Matrigel(MiM pads. Matrigel 1 was purchased from Collaborative Research Inc. (Bedford, MA, USA). For pad formation, $1.0 \mathrm{ml}$ of the Matrigel solution $(9.67 \mathrm{mg} / \mathrm{ml}$ ) was added to sterile Permanox (Nunc, Inc., Naperville, IL, USA) tissue culture dishes $(35 \times 10 \mathrm{~mm})$ and left to polymerize for $30 \mathrm{~min}$ at $37^{\circ} \mathrm{C}$. The pads were then rinsed with culture medium and left to equilibrate overnight in the incubator. They were rinsed with fresh medium before the addition of mouse or guinea-pig blastocysts.

Transmission electron microscopy. After culture for 48 or $72 \mathrm{~h}$, the pads were rinsed with PBS and fixed in $2 \%$ glutaraldehyde in $0.1 \mathrm{M}$ cacodylate buffer $(\mathrm{pH} 7 \cdot 3)$ for $1 \mathrm{~h}$. Pads were subsequently washed in $0.1 \mathrm{M}$ cacodylate buffer three times for $15 \mathrm{~min}$ each. The pads were then fixed in $1 \%$ osmium tetroxide in $0.1 \mathrm{M}$ cacodylate buffer $(\mathrm{pH} 7 \cdot 3$ ) and rinsed three times for $10 \mathrm{~min}$ each in distilled water. The pads were stained en bloc with $1 \%$ aqueous uranyl acetate for $1 \mathrm{~h}$ followed by three rinses in distilled water for $5 \mathrm{~min}$ each. Dehydration was performed in a graded series of ethanol solutions followed by two 15 -min changes in $100 \%$ propylene oxide. They were then infiltrated with mixtures of propylene oxide and Epon 812 embedding mixture (2:1, 1:1 and 1:2) for 30 min each followed by $100 \%$ Epon 812 overnight at room temperature. The next day, a fresh exchange of the plastic was performed and after $1 \mathrm{~h}$ the pads were polymerized at $65^{\circ} \mathrm{C}$ for $24 \mathrm{~h}$.

Embedded tissues were sectioned on a Sorval MT2-B ultramicrotome using diamond knives. Thick $(0 \cdot 5-1 \cdot 0 \mu \mathrm{m})$ sections were fixed to glass slides and stained with $1 \%$ toluidine blue in $1 \%$ sodium borate solution. Thin sections $(60-$ $100 \mathrm{~nm}$ ) were collected on uncoated I50 or 200 mesh nickel grids and stained with $50 \%$ ethanolic, saturated uranylacetate followed by lead citrate. The grids were then examined by means of a Hitachi $600 \mathrm{H}$ electron microscope with images recorded using Kodak SO-163 negative film.

\section{Results}

\section{Embryo culture}

Following the placement of zona-pellucida-encased mouse blastocysts and zona-pellucida-free guinea-pig blastocysts on the surface of either Matrigel(iM) or type I collagen pads, the pads were left undisturbed for $48 \mathrm{~h}$ to allow for attachment to the matrix surface. Both mouse and guinea-pig blastocysts attached to the surface of Matrigel(Mi) and type I collagen. There was no significant difference in blastocyst viability and the rate of blastocyst attachment to either Matrigel(M) or type I collagen, although mouse blastocyst attachment to Matrigel(MM) was lower than to type I collagen.

We were particularly interested in ovulation rates, embryo recovery and in-vitro culture of guinea-pig blastocysts. Forty-six guinea-pigs were mated, displayed a vaginal plug and were used in this experiment; $91 \cdot 3 \%$ ( 42 of 46$)$ had ovulated on the evidence of microscopic examination of their ovaries; an average of 3.29 (138 of 42) ovulation sites per pair of ovaries was recorded. We recovered 87 guinea-pig blastocysts for an average of 2.07 blastocysts per animal which resulted in a $63 \%$ recovery rate. However, 12 of the 42 guinea pigs which had ovulated failed to yield any blastocysts. This may indicate abnormal fertilization, premature embryonic death, or inefficient flushing of the uterus.

The culture medium and in-vitro embryo culture system permits embryonic growth and development for up to $72 \mathrm{~h}$ as shown by trophoblast cell interaction with the extracellular matrices and continued mitotic activity of trophoblast and other embryonic cells. The enzymatic removal of the guinea-pig zona pellucida was necessary. In earlier work (data not shown), we observed that guinea-pig blastocysts collected late on Day 5 failed to hatch completely from their zona pellucida. We did observe trophoblast processes piercing the zona pellucida, but not complete hatching. These results were similar to those of Parr (1973). The treatment of guinea-pig blastocysts with 
pronase at $37^{\circ} \mathrm{C}$ for $2-5$ min completely removed the zona pellucida and did not affect the rate of attachment or viability when compared with mouse blastocysts which had not been exposed to pronase. Recently, we have collected a few guinea-pig blastocysts on Day 6 and 27\% (4 of 15) have hatched completely in vitro.

\section{Matrigel(MI)}

By $48 \mathrm{~h}$, the majority of mouse and guinea-pig blastocysts had attached to the surface of the Matrigel(im) pad, but none displayed dramatic interactions with this matrix. Light microscopy of blastocysts indicated that they remained viable for up to $72 \mathrm{~h}$, but they did not display significant trophoblast cell outgrowth or invasive activity with Matrigelim (Fig. 1). Mouse and guinea-pig blastocysts were occasionally seen in a slight depression in the Matrigel@ pad, but this may reflect more of a physical interaction with the pad rather than an enzymatic or cellular interaction. With transmission electron microscopy, trophoblast cells were seen to be oriented parallel to the surface of the gel. Mouse trophoblast cells were devoid of microvilli (Fig. 2) and contained numerous mitochondria and rough endoplasmic reticulum cisternae within their cytoplasm; lipid vacuoles were observed. Guinea-pig trophoblast cells also displayed little interaction with the Matrigel(Mi) surface at either 48 or $72 \mathrm{~h}$ in culture. Occasionally small microvilli were observed extending out from the cells, but these did not disrupt the matrix (Fig. 3); the cytoplasm was similar to that of the mouse trophoblast cell. There was no evidence of focal alteration of the matrix in the vicinity of the blastocyst.

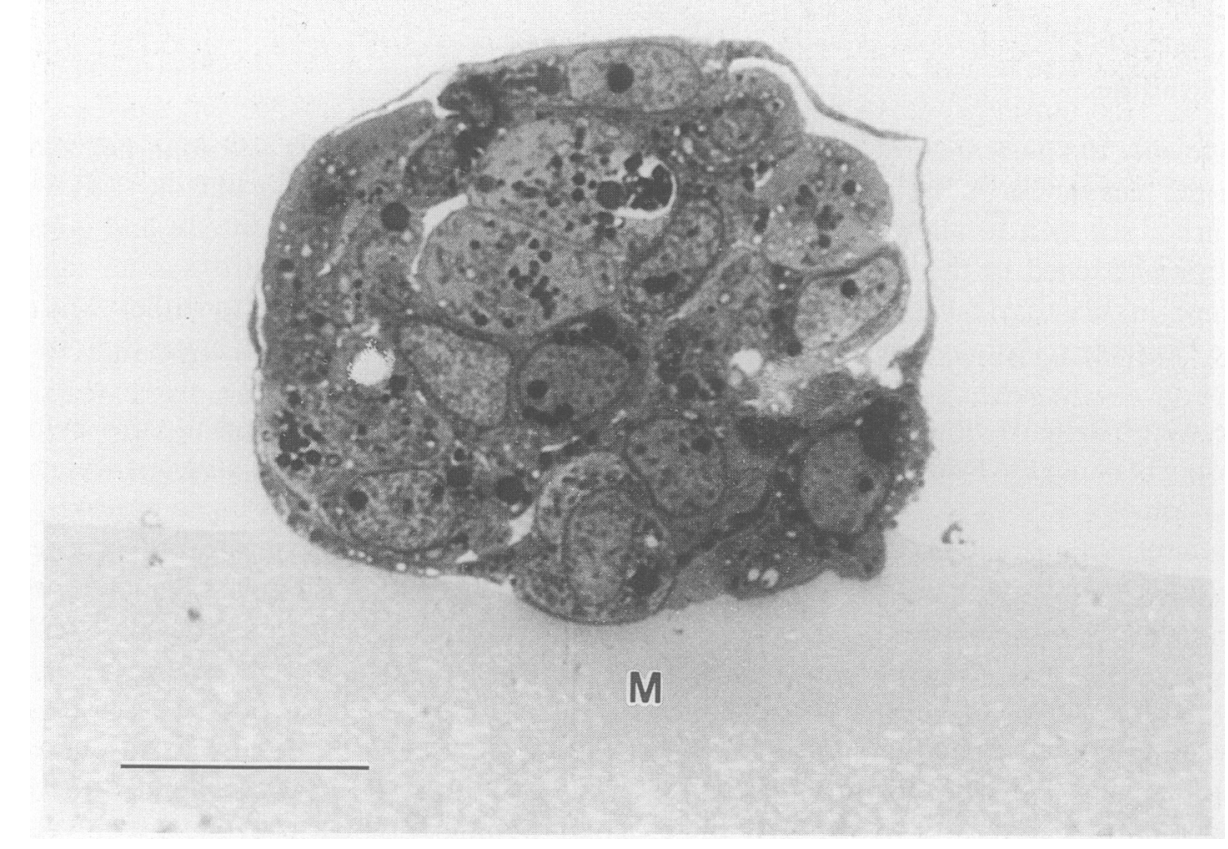

Fig. 1. Light micrograph of a mouse blastocyst attached to Matrigel $(\mathrm{M})$ (M) after $72 \mathrm{~h}$ in culture. The blastocyst has hatched from the zona pellucida and attached to the surface of the gel, but trophoblast outgrowth or penetration into the gel has not occurred. Toluidine blue. Bar, $100 \mu \mathrm{m}$. 


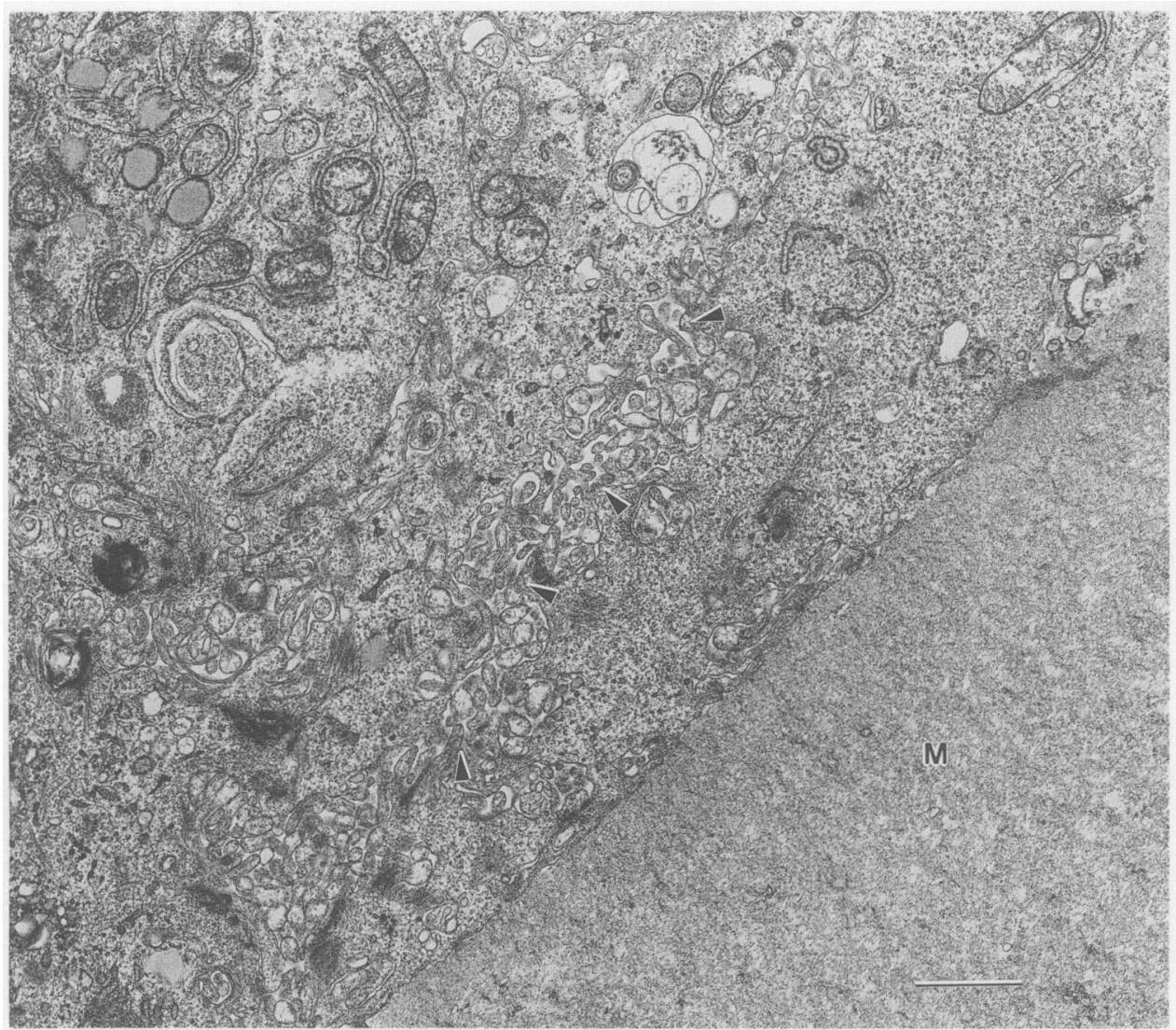

Fig. 2. Transmission electron micrograph of a mouse blastocyst attached to Matrigel(M) (M) after $72 \mathrm{~h}$ in culture. Adjacent trophoblast cells exhibit numerous interdigitating cell processes (arrow heads), but there is little indication of interaction with the Matrigel(iim) surface. Bar, $1 \mu \mathrm{m}$.

\section{Type I collagen}

By $48 \mathrm{~h}$, both mouse and guinea pig blastocysts had attached to the surface of the type I collagen pads. In contrast to Matrigel(Mim, blastocysts which attached to and interacted with type I collagen developed extensive trophoblast cell processes which extended into the matrix (Fig. 4). At $48 \mathrm{~h}$, short, slender trophoblast cell processes were beginning to penetrate the matrix. The cytoplasm of the process appeared to be homogeneous and have few cell organelles (Fig. 5). The collagen matrix was altered in appearance and was similar to the trophoblast cell processes. Secondary lysosome-like vacuoles were observed within trophoblast cells; numerous cell protrusions were observed between adjacent trophoblast cells and between trophoblast cells and the matrix.

After $72 \mathrm{~h}$ in culture, the number of trophoblast cytoplasmic processes had increased and, although the exact length of the protrusions could not be traced exactly, they appeared to have penetrated deeper into the type I collagen matrix (Fig. 6). Guinea-pig trophoblast cell processes were composed of slender anastomosing processes which extended into the matrix; mouse trophoblast cell processes tended to be broader. Numerous microfilaments aligned parallel to the long axis of the trophoblast process were observed at the matrix interface. The cytoplasmic projections contained numerous ribosomes and fibrous components (Fig. 7). The guinea-pig trophoblast cells in culture appeared to be syncytial; by $72 \mathrm{~h}$, matrix appeared to be present within the cells (Fig. 8). It is possible that the cells were engulfing the matrix by endocytosis or phagocytosis or that adjacent trophoblast cell projections had fused. The cytoplasmic processes interdigitated and desmosomes 


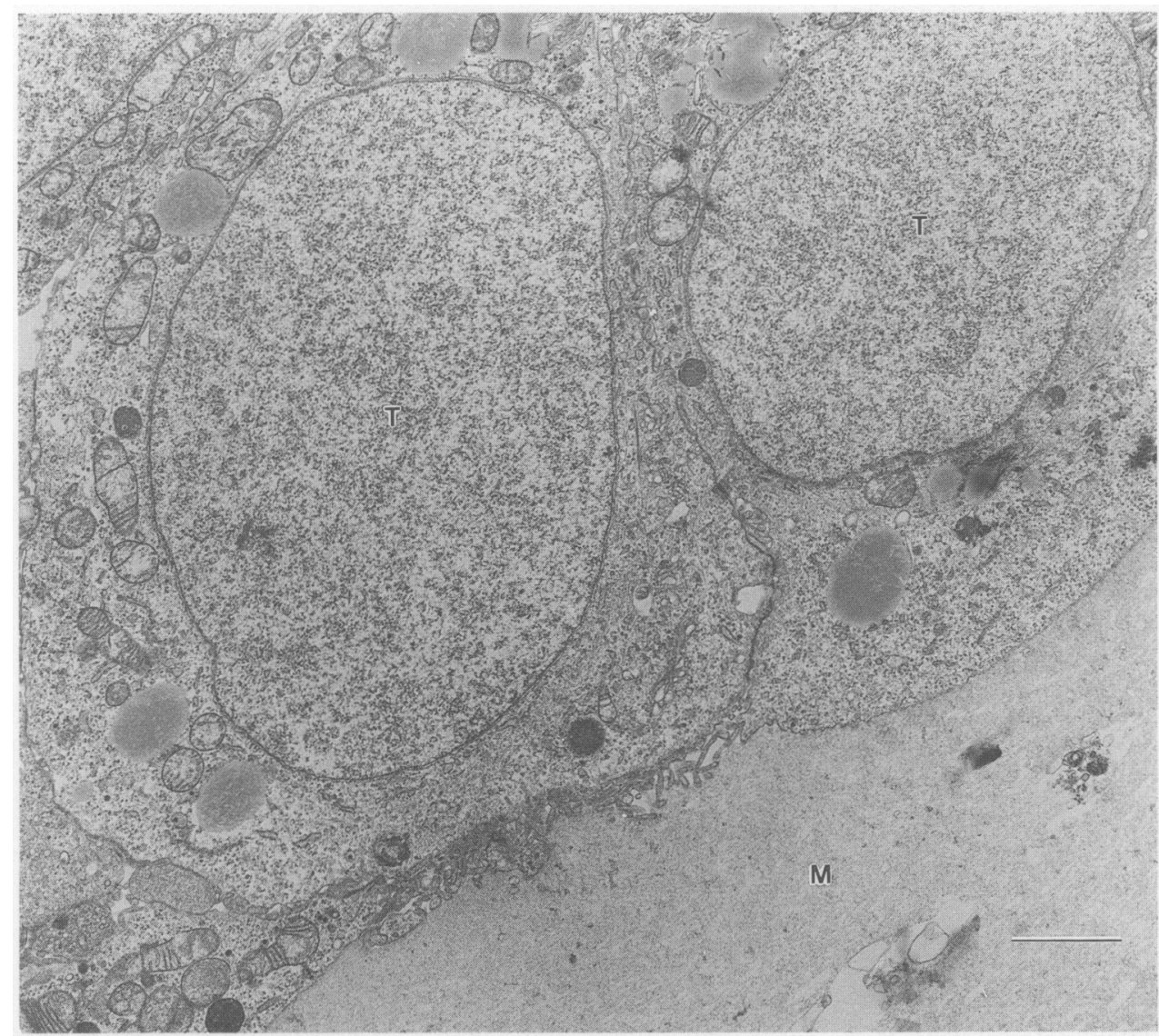

Fig. 3. Transmission electron micrograph of a guinea-pig blastocyst attached to Matrigel $(M)$ (M) after $72 \mathrm{~h}$ in culture. A few short microvilli have formed, but there is little evidence of trophoblast cell $(\mathrm{T})$ interaction with the matrix. Bar, $2 \mu \mathrm{m}$.

were occasionally observed between adjacent processes. Microtubules were abundant within the cytoplasm of the process (Fig. 8). Secretory granules or evidence for secretory activity were absent. There was evidence of an alteration of the type I collagen in the vicinity of individual trophoblast processes. The matrix in the vicinity of the trophoblast cell process was less electron-dense. This effect appeared to be very localized since there was no general degradation of the matrix.

\section{Discussion}

Since implantation of the blastocyst into the endometrium involves interactions which are difficult to analyse and alter in vivo, we used a reconstituted basal lamina matrix preparation (Matrigel (ख⿰亻) and interstitial type I collagen to examine, at the ultrastructural level, the in-vitro interactions of trophoblast cells with these extracellular matrices. In addition, by the use of mouse and guinea-pig blastocysts we examined how different trophoblast cell populations interact with extracellular matrices. Since guinea-pigs implant by an intrusive mechanism and mice by a displacement mechanism (Enders \& Schlafke, 1972), it was possible that we would observe differences in trophoblast cell interaction with the extracellular matrices.

Matrigel $\left(\mathrm{M}_{\mathrm{M}}\right.$ is a solubilized extract of basal lamina material from Engelbreth-Holm-Swarm (EHS) mouse tumour cells and contains laminin, type IV collagen, heparan sulphate proteoglycan 


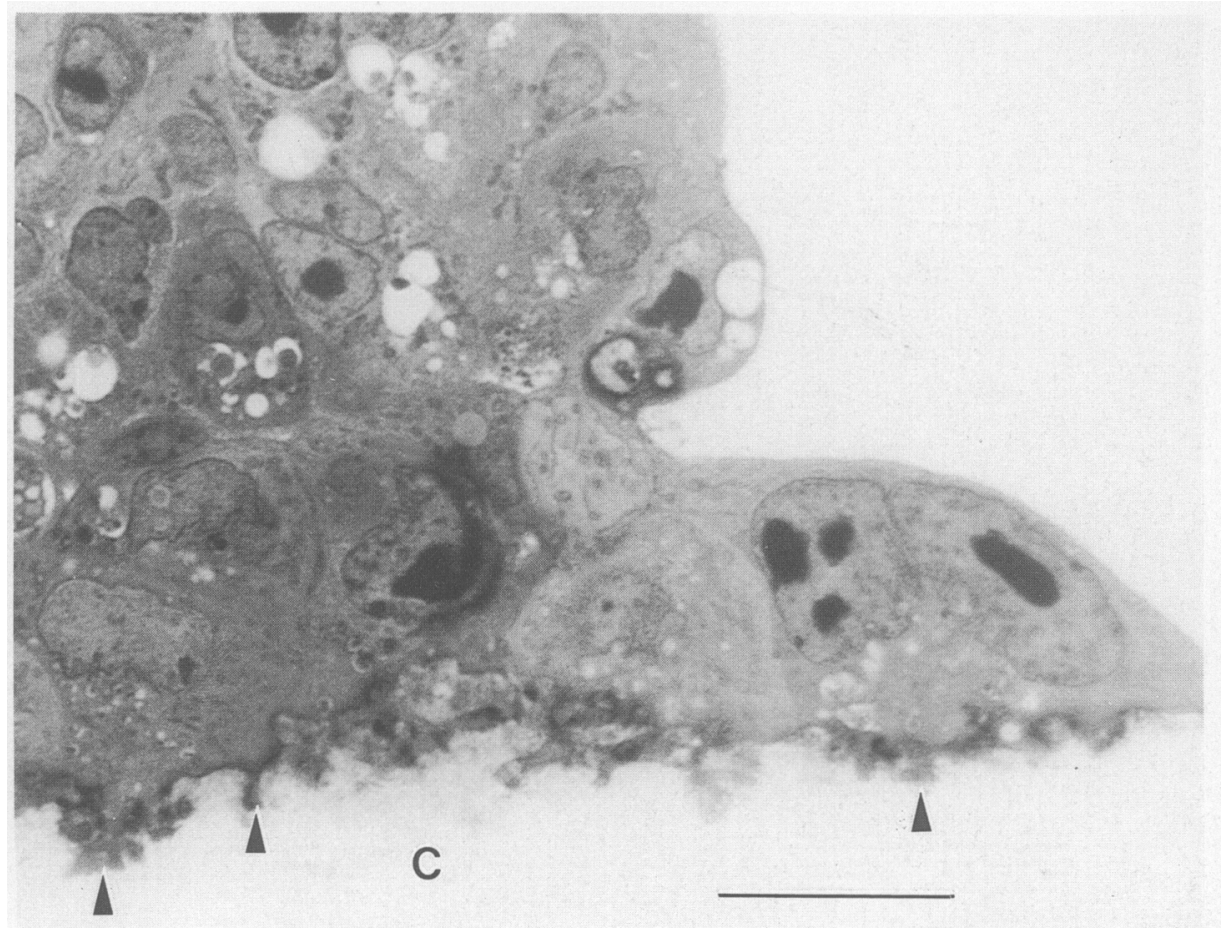

Fig. 4. Light micrograph of a guinea-pig blastocyst attached to type I collagen (C) after $48 \mathrm{~h}$ in culture. Trophoblast cells have spread along the surface of the matrix and numerous trophoblast cell processes (arrow heads) have extended into the matrix. Toluidine blue. Bar, $20 \mu \mathrm{m}$.

and entactin (Kleinman et al., 1986). Our results, using a polymerized pad of Matrigel(i⿵冂, demonstrated that zona-pellucida-free mouse and guinea-pig blastocysts have the ability to attach to this matrix, but trophoblast cells failed to spread on the surface or penetrate into the gel. These observations are identical to those of Welsh \& Enders (1989) who examined blastocyst interaction in mice and rats with several extracellular matrices including Matrigelim. The lack of interaction of trophoblast cells with Matrigel (iim is interesting, since Matrigel $(\times m$ has been used extensively to enhance the in-vitro growth of epithelial cells and has been reported to affect morphology and epithelial cell phenotypic expression. Potentially four factors interact to explain the inability of mouse or guinea-pig trophoblast cells to interact appreciably with Matrigel(․‥ These include: (a)

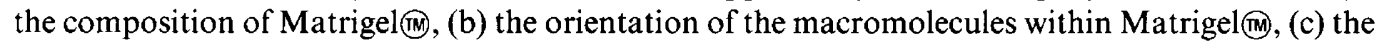
degradative enzyme capabilities of trophoblast cells at various stages of implantation and (d) an interactive role of decidual cells. These factors are not mutually exclusive, but may be interdependent.

Matrigel im is a product of a mouse sarcoma tumour cell line and the exact composition of the macromolecules within the matrix is not known. Lee \& Dunbar (1989) have reported the presence of at least two proteins which are released from Matrigel $($ mads into culture medium. This raises the possibility that proteins released from the Matrigel 10 pad may adversely influence blastocyst development and/or trophoblast cell outgrowth. Natural basal laminae are not homogeneous structures, but differ in macromolecular composition (Leu et al., 1986). This may be reflected in the ability of blastocysts to penetrate certain basal laminae, but not others. For example, although both ferret and rhesus monkey embryos can penetrate the basal lamina associated with the endometrial luminal epithelial layer, rhesus monkey embryos have the additional capability to penetrate the basal lamina associated with maternal blood vessels, but ferret embryos lack this ability 


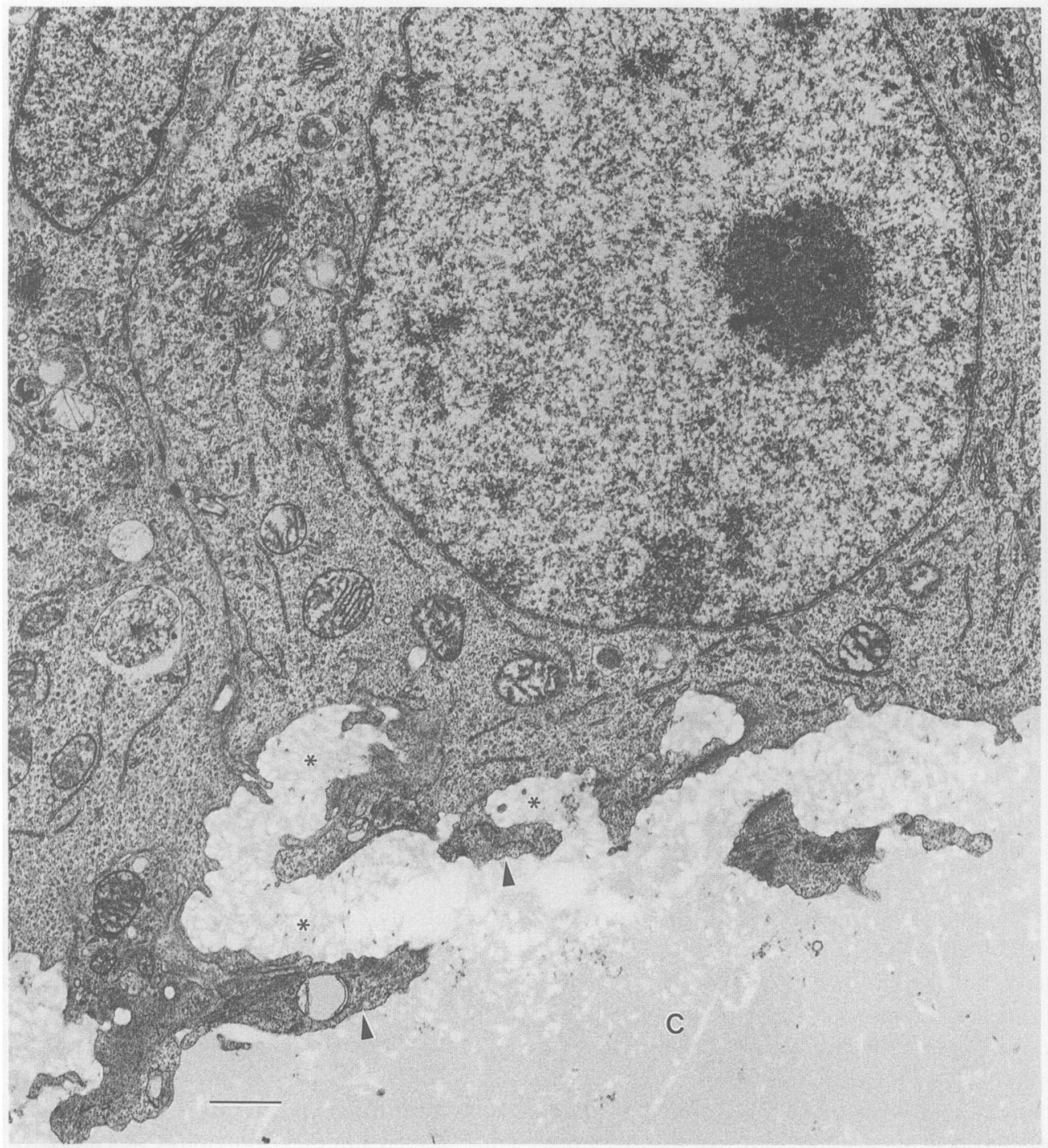

Fig. 5. Transmission electron micrograph of a mouse blastocyst attached to type I collagen (C) after $48 \mathrm{~h}$ in culture. Short trophoblast cell processes (arrow heads) are beginning to penetrate into the matrix. The collagen matrix is altered in appearance in close approximation to the trophoblast cell processes $\left({ }^{*}\right)$. Bar, $1 \mu \mathrm{m}$.

(Weitlauf, 1988). Thus, although Matrigel(Mi) is used as a substitute for the basal lamina, it contains other unidentified proteins and may not mimic the basal laminae met by the blastocyst during implantation. It is possible that the degradative capability of trophoblast cells on Matrigel $(M$ may not be optimized in comparison with other extracellular matrices.

A second explanation may be that the macromolecular spatial organization of the Matrigel $(\mathrm{M}$ pad does not allow trophoblast cell interaction. This type of difficulty has been suggested with other basal laminae. For example, it has been shown in our laboratory that mouse trophoblast cells are capable of attachment and outgrowth, but not penetration of the bovine lens capsule, a natural extracellular matrix (Cammarata et al., 1987). We suggested that mouse trophoblast cells could not penetrate the lens capsule because of the high degree of spatial organization of the capsule rather 


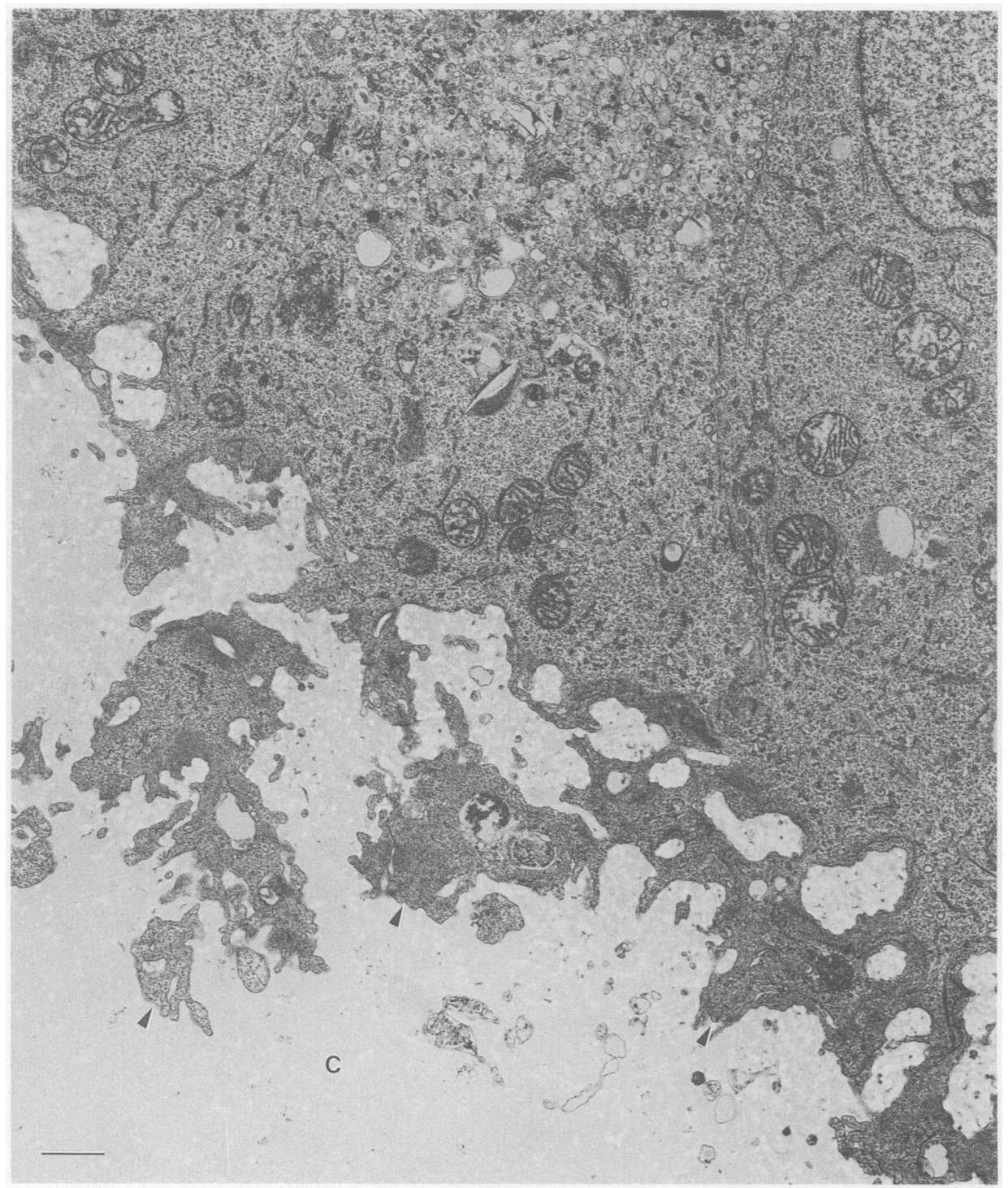

Fig. 6. Transmission electron micrograph of a mouse blastocyst attached to type I collagen (C) after $72 \mathrm{~h}$ in culture. In comparison with Fig. 5, there are now more trophoblast cell processes (arrow heads) extending into the collagen matrix and they have extended deeper into the matrix, indicating active penetration. Bar, $1 \mu \mathrm{m}$.

than because of its composition. Thus, the molecular arrangement of the matrix components may also determine whether trophoblast cells are capable of disrupting the matrix.

Thirdly, as pointed out by Welsh \& Enders (1989), the potential for degradative enzymatic action by trophoblast cells may vary among species and within the same trophoblast cell population at different times during gestation. There have been several attempts to examine the in-vitro interaction of trophoblast cells on cellular monolayers (Sherman \& Salomon, 1975; Glass et al., 1979; Van Blerkom \& Chavez, 1981), but few dealing with extracellular matrices. Glass et al. (1983) and Welsh \& Enders (1989) have shown that mouse trophoblast cells are capable of disrupting a complex extracellular matrix which was produced by vascular smooth muscle cells. Welsh \& Enders 


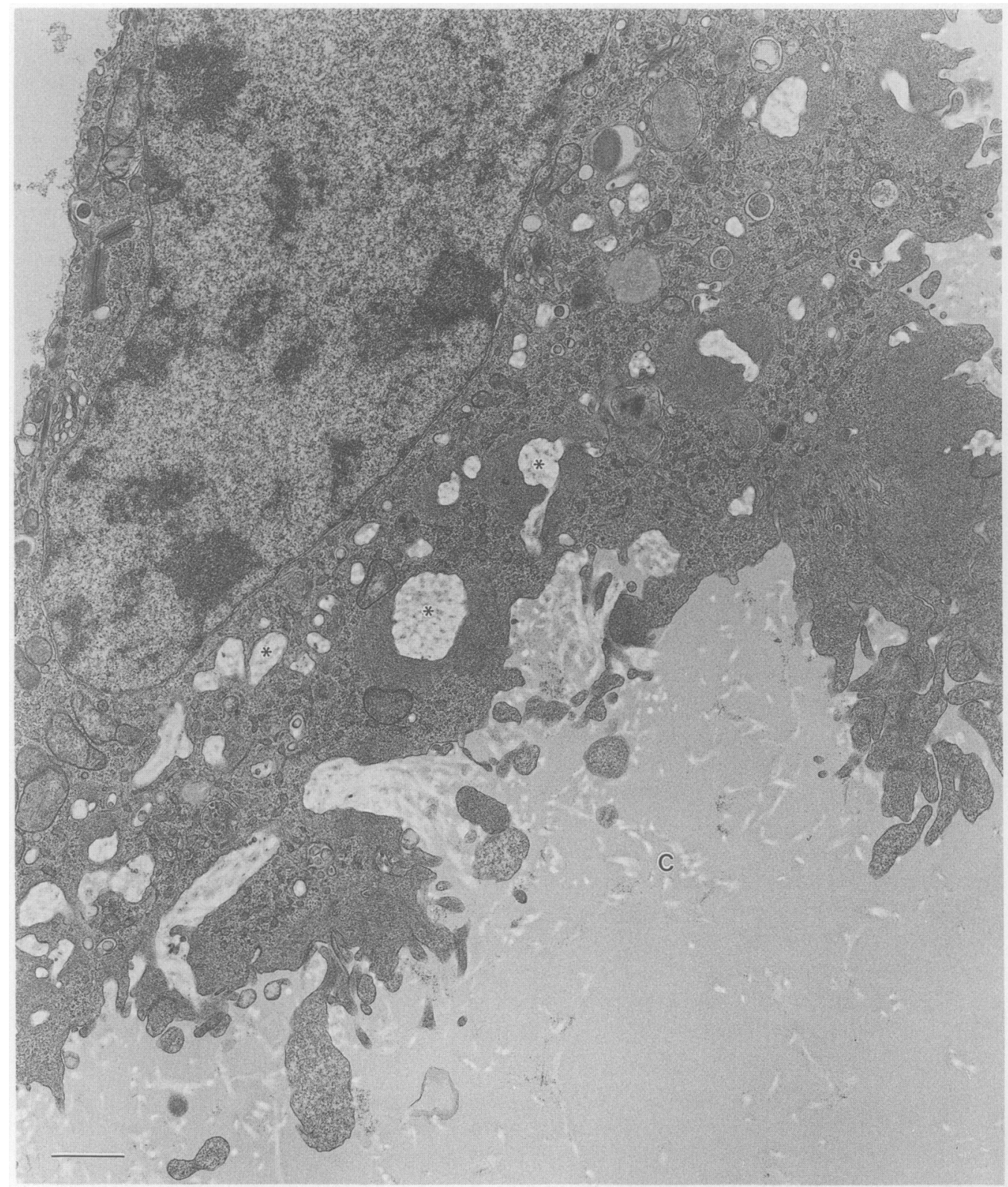

Fig. 7. Transmission electron micrograph of a guinea-pig blastocyst attached to type I collagen (C) after $72 \mathrm{~h}$ in culture. Trophoblast cell processes are wider than in mouse blastocysts. Note the modification of the collagen matrix close to the trophoblast cell processes. Trophoblast cells contain numerous secondary lysosomes and microfilaments extend into the cell processes. Areas of matrix entrapped by cell processes can be seen $\left(^{*}\right)$. Bar, $1 \mu \mathrm{m}$.

(1989) examined the interaction of mouse and rat trophoblast cells with three other complex extracellular matrices: rat corneal matrix, human amnion matrix and Matrigel $\mathrm{M}$. Mouse trophoblast cells were capable of disrupting only vascular, smooth-muscle-cell matrix; rat trophoblast cells failed to disrupt any of the matrices examined. This finding is interesting since both mouse and rat 


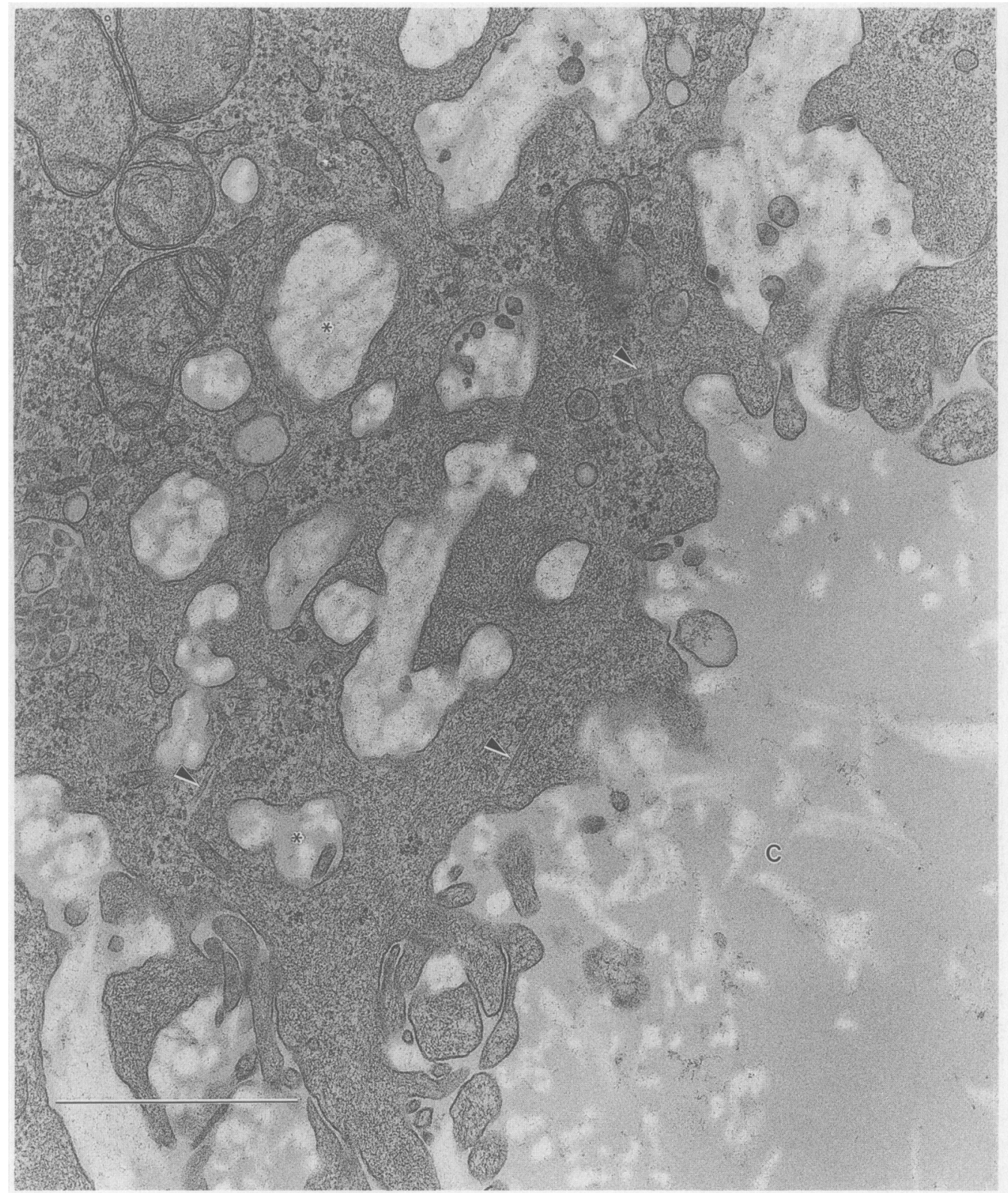

Fig. 8. Higher magnification transmission electron micrograph of several guinea-pig trophoblast cell projections into the collagen $(\mathrm{C})$ matrix. The processes tend to be devoid of organelles, but contain dense aggregates of microfilaments and numerous microtubules (arrow heads). The cellular projections appear to fuse and entrap collagen matrix $\left(^{*}\right)$. Bar, $1 \mu \mathrm{m}$.

embryos are considered to implant by the same mechanism, but would appear to interact with extracellular matrices by different mechanisms.

An alternative explanation for the lack of interaction of trophoblast cells with this basal lamina matrix may be the requirement for functional decidual cells. In both displacement and intrusive 
mechanisms of implantation, trophoblast cell processes pause at the endometrial basal lamina and are disposed along it for a period before traversing into the connective tissue stroma (Weitlauf, 1988). The underlying decidual cells may play a role in the penetration of embryos through the basal lamina. Stromal cells or their derivatives are capable of altering different types of extracellular matrices as shown by their ability to penetrate the uterine luminal basal lamina before trophoblast invasion (Schlafke \& Enders, 1975) as well as the basal lamina of maternal blood vessels (Schlafke et al., 1985). Since our in-vitro system lacked the decidual cell component, it is possible that mouse and guinea-pig blastocysts are incapable of the enzymatic breakdown of basal lamina macromolecules as constituted within Matrigel $(\mathrm{m})$ and require the presence of decidual cells. Since mouse and guinea-pig blastocysts do not alter Matrigel(M), it is possible that they cannot produce type IV collagenase or other degradative enzymes, but do produce factors which stimulate decidual cells to release collagenases. This type of inductive hypothesis has been proposed for metastatic tumours by Woolley et al. (1980). Also, Wirl \& Frick (1979) concluded that collagenolytic activity may be a product of the host in response to the invading tumour and not a product of the tumour itself.

In contrast to Matrigel(M, both mouse and guinea-pig trophoblast cells displayed active interaction with and penetration of interstitial type I collagen. By $48 \mathrm{~h}$ in culture, trophoblast cell processes had spread on the surface of the collagen pad and had begun to penetrate into the matrix. Initially, short cellular processes were observed, but, by $72 \mathrm{~h}$, the processes had extended deeper into the lattice of reconstituted fibrils indicating active cell growth. In guinea-pig, the processes that had penetrated the matrix were similar to those described in relation to implantation (Enders \& Schlafke, 1969). The alteration in the collagen gel in close association with trophoblast cell processes may indicate increased proteolytic activity, which causes focal alterations in the surrounding extracellular matrix. Collagenases, cathepsins, elastase, plasminogen activator and other neutral proteases are frequently associated with matrix degradation (Pauli \& Knudson, 1988). Trophoblast cell invasiveness may require degradation of matrix macromolecules as is associated with metastasizing tumour cells.

The localized, focal alteration in collagen suggests a microenvironmentally dependent activity of collagenase or some other enzyme. Since secretory granules were not observed within trophoblast cell processes, it is probable that membrane bound proteases are involved in the invasion of the collagen matrix. The presence of plasminogen activator or collagenase bound to the trophoblast cell membrane would help facilitate migration through the collagen gel. Migrating tumour cells are known to produce large quantities of plasminogen activator and to deposit some of the product into the substratum (Quigley, 1979). Thus, the interaction of membrane-bound proteases with extracellular matrix macromolecules could provide an efficient mechanism for trophoblast cellular processes to attach to and detach from the matrix during migration.

Although the interstitial collagen model lacks components found in situ (e.g. fibroblasts, vascular elements and proteoglycans), the hydrated collagen gel does mimic the organizational framework of the connective tissue stroma. Macromolecules within the interstitial extracellular matrix provide structural support to the implanting embryo. These macromolecules may provide signals to the implanting embryo, thus fulfilling an instructive role. The remodelling of the extracellular matrix during implantation involves many complex interactions between the trophoblast cell surface and various matrix constituents which we are just beginning to understand.

Although the basic components of the extracellular matrices used in various in-vitro experiments may be similar to uterine extracellular matrices, the spatial arrangement and proportions of the macromolecules within uterine extracellular matrices may be quite different. For example, there is at least one report that the rat endometrium is rich in type III collagen (Grinnell \& Head, 1982). It may be possible to develop a more suitable model by adding uterine epithelial cells to the surfaces of the various extracellular matrices and stromal/decidual cells within the matrix. This would allow trophoblast cells to interact with both epithelial cells sitting on an extracellular matrix and decidual cells within the matrix. These studies are currently being pursued. 
The authors wish to acknowledge the support of the National Pituitary Hormone Program, University of Maryland School of Medicine, Baltimore, MD, USA for the gift of PMSG. This research was supported by NIH grant HD-25638.

\section{References}

Cammarata, P.R., Oakford, L., Cantu-Crouch, D. \& Wordinger, R.J. (1987) Attachment of blastocysts to lens capsule: a model system from trophoblastepithelial cell interaction on a natural basement membrane. Cell Tissue Res. 250, 633-640.

Enders, A.C. \& Schlafke, S. (1969) Cytological aspects of trophoblast-uterine interaction in early implantation. Am. J. Anat. 125, 1-30.

Enders, A.C. \& Schlafke, S. (1972) Implantation in the ferret: epithelial penetration. Am. J. Anat. 133, 291-316.

Finn, C.A. \& Hinchliffe, J.R. (1964) The reaction of the mouse uterus during implantation and deciduoma formation as demonstrated by changes in the distribution of alkaline phosphatase. J. Reprod. Fert. 8, 331-338.

Glass, R.H., Spindle, A.I. \& Pedersen, R.A. (1979) Mouse embryo attachment to substratum and interaction of trophoblast with cultured cells. J. exp. Zool. 208, $327-336$.

Glass, R.H., Aggeler, J., Spindle, A., Pedersen, R.A. \& Werb, Z. (1983) Degradation of extracellular matrix by mouse trophoblast outgrowths: a model for implantation. J. Cell Biol. 96, 1108-1116.

Grinnell, F. \& Head, J.R. (1982) Fibronectin and cell shape in vivo: studies on the endometrium during pregnancy. J. Cell Biol. 94, 596-606.

Kleinman, J.K., McGarvey, M.L., Hassell, J.R., Star, V.L., Cannon, F.B., Laurie, G.W. \& Martin, G.R. (1986) Basement membrane complexes with biological activity. Biochemistry 25, 312-318.

Lee, V.H. \& Dunbar, B.S. (1989) Analysis of Matrigel (EHS Biomatrix) proteins using two-dimensional polyacrylamide gel electrophoresis during cell culture. J. Cell Biol. 109, 322 a.

Leu, F.J., Engvall, E. \& Damjanov, l. (1986) Heterogeneity of basement membranes of the human genito-urinary tract revealed by sequential immunofluorescence staining with monoclonal antibodies to laminin. $J$. Histochem. Cytochem. 34, 483489.

Parr, E.L. (1973) Shedding of the zona pellucida by guinea pig blastocysts: an ultrastructural study. Biol. Reprod. 8, 531-544.

Pauli, B.U. \& Knudson, W. (1988) Tumor invasion: a consequence of destructive and compositional matrix alterations. Human Pathol. 19, 628-639.
Quigley, J.P. (1979) Proteolytic enzymes of normal and malignant cells. In Surfaces of Normal and Malignant Cells, pp. 247-285. Ed. R. O. Hynes. John Wiley and Sons, New York.

Schlafke, S. \& Enders, A.C. (1975) Cellular basis of interaction between trophoblast and uterus at implantation. Biol. Reprod. 12, 41-65.

Schlafke, S., Welsh, A.O. \& Enders, A.C. (1985) Penetration of the basal lamina of the uterine luminal epithelium during implantation in the rat. Anat. Rec. 212, 47-56.

Sherman, M.I. \& Salomon, D.S. (1975) The relationships between the early mouse embryo and its environment. In The Developmental Biology of Reproduction, pp. 277-309. Ed. J. Papaconstantinou. Academic Press, New York.

Van Blerkom, J. \& Chavez, D.J. (1981) Morphodynamics of outgrowths of mouse trophoblast in the presence and absence of a monolayer of uterine epithelium. Am. J. Anat. 167, 143-155.

Weitlauf, H.M. (1988) Biology of implantation. In The Physiology of Reproduction, pp. 231-262. Eds E. Knobil, J. Neill, L. Ewing, G. Greenwald, L. Markert \& D. Pfaff. Raven Press Ltd, New York.

Welsh, A.O. \& Enders, A.C. (1987) Trophoblast-decidual cell interactions and establishment of maternal blood circulation in the parietal yolk sac placenta of the rat. Anat. Rec. 217, 203-219.

Welsh, A.O. \& Enders, A.C. (1989) Comparisons of the ability of cells from rat and mouse blastocysts and rat uterus to alter complex extracellular matrix in vitro. In Blastocyst Implantation, pp. 55-74. Ed. K. Yoshinaga. Adams Publishing Group Ltd, Boston, USA.

Wirl, G. \& Frick, J. (1979) Collagenase-A marker enzyme in human bladder cancer? Urol. Res. 7, 103-108.

Woolley, D.E., Tetlow, L.C., Mooney, C.J. \& Evanson, J.M. (1980) Human collagenase and its extracellular inhibitors in relation to tumor invasiveness. In Proteinases and Tumor Invasion, pp. 97-115. Eds P. Strauli, A. J. Barrett \& A. Baici. Raven Press, New York.

Received 13 February 1991 